\title{
Spontaneous breathing trial and post- extubation work of breathing in morbidly obese critically ill patients
}

\author{
Martin Mahul ${ }^{1 \dagger}$, Boris Jung ${ }^{1,4 \dagger}$, Fabrice Galia ${ }^{1}$, Nicolas Molinari ${ }^{2}$, Audrey de Jong ${ }^{1}$, Yannaël Coisel ${ }^{1,4}$, \\ Rosanna Vaschetto ${ }^{3}$, Stefan Matecki ${ }^{4}$, Gérald Chanques ${ }^{1,4}$, Laurent Brochard ${ }^{5,6}$ and Samir Jaber ${ }^{1,4^{*}}$
}

\begin{abstract}
Background: Predicting whether an obese critically ill patient can be successfully extubated may be specially challenging. Several weaning tests have been described but no physiological study has evaluated the weaning test that would best reflect the post-extubation inspiratory effort.

Methods: This was a physiological randomized crossover study in a medical and surgical single-center Intensive Care Unit, in patients with body mass index (BMI) $>35 \mathrm{~kg} / \mathrm{m}^{2}$ who were mechanically ventilated for more than $24 \mathrm{~h}$ and underwent a weaning test. After randomization, 17 patients were explored using five settings : pressure support ventilation (PSV) 7 and positive end-expiratory pressure (PEEP) $7 \mathrm{cmH} 2 \mathrm{O}$; PSV 0 and PEEP 7cmH2O; PSV 7 and PEEP 0 $\mathrm{cmH2O}$; PSV 0 and PEEP $0 \mathrm{cmH2O}$; and a T piece, and after extubation. To further minimize interaction between each setting, a period of baseline ventilation was performed between each step of the study. We hypothesized that the post-extubation work of breathing (WOB) would be similar to the T-tube WOB.

Results: Respiratory variables and esophageal and gastric pressure were recorded. Inspiratory muscle effort was calculated as the esophageal and trans-diaphragmatic pressure time products and WOB. Sixteen obese patients (BMl $44 \mathrm{~kg} / \mathrm{m}^{2} \pm 8$ ) were included and successfully extubated. Post-extubation inspiratory effort, calculated by WOB, was $1.56 \mathrm{~J} / \mathrm{L} \pm 0.50$, not statistically different from the T piece $(1.57 \mathrm{~J} / \mathrm{L} \pm 0.56)$ or PSV 0 and PEEP $0 \mathrm{cmH}_{2} \mathrm{O}(1.58 \mathrm{~J} / \mathrm{L}$ $\pm 0.57)$, whatever the index of inspiratory effort. The three tests that maintained pressure support statistically underestimated post-extubation inspiratory effort (WOB $0.69 \mathrm{~J} / \mathrm{L} \pm 0.31,1.15 \mathrm{~J} / \mathrm{L} \pm 0.39$ and $1.09 \mathrm{~J} / \mathrm{L} \pm 0.49$, respectively, $p<0.001)$. Respiratory mechanics and arterial blood gases did not differ between the five tests and the post-extubation condition.

Conclusions: In obese patients, inspiratory effort measured during weaning tests with either a T-piece or a PSV 0 and PEEP 0 was not different to post-extubation inspiratory effort. In contrast, weaning tests with positive pressure overestimated post-extubation inspiratory effort.
\end{abstract}

Trial registration: Clinical trial.gov (reference NCT01616901), 2012, June 4th

Keywords: Weaning, Mechanical ventilation, Obese, Work of breathing, Acute respiratory failure

\footnotetext{
* Correspondence: s-jaber@chu-montpellier.fr

${ }^{\dagger}$ Equal contributors

'Intensive Care Unit, Anaesthesia and Critical Care Department, Saint Eloi Teaching Hospital, Centre Hospitalier Universitaire Montpellier, 80 avenue Augustin Fliche, F-34295 Montpellier, Cedex 5, France

${ }^{4}$ Centre National de la Recherche Scientifique (CNRS 9214) - Institut National

de la Santé et de la Recherche Médicale (INSERM U-1046), Montpellier

University, Montpellier, France

Full list of author information is available at the end of the article
} 


\section{Background}

Extubation is a critical decision in the Intensive Care Unit (ICU). Extubation failure may occur in up to $20 \%$ [1] of patients and is associated with morbidity. Excessive and non-sustainable work of breathing (WOB) is likely a major reason for extubation failure [2-5]. Evaluation of how the critically ill patient is breathing with no assistance or a minimal level of assistance (the period known as the weaning test or the spontaneous breathing trial) [4] is therefore recommended before extubation $[3,4,6,7]$. Different weaning tests are suggested for non-selected adult patients: a T-piece trial (oxygen supply without positive pressure), continuous positive airway pressure (CPAP) and low pressure support ventilation (PSV), with a low level of PSV, from 5 to 8 $\mathrm{cmH}_{2} \mathrm{O}$, to compensate for the imposed workload due to the ventilator circuit $[3,4,6,7]$. Although these weaning tests are not equivalent in term of the WOB $[8,9]$ and studies are underpowered to assess the risk of extubation failure, they are recommended to assess whether a patient is ready to be extubated $[3,6]$.

Predicting whether an obese critically ill patient can be successfully extubated may be specially challenging. Obesity decreases respiratory system compliance, inspiratory and expiratory lung volumes, functional residual capacity, upper airway mechanical function and neuromuscular strength [10]. Moreover, in obese patients, oxygen consumption is increased, with a high proportion of this consumption spent in the WOB [11-13]. Although the $\mathrm{T}$ piece, CPAP and low PSV levels have been used to reproduce postextubation conditions in non-selected critically ill patients, the weaning test modality that would best reproduce post-extubation inspiratory effort (WOB and pressure time product indexes) in obese critically ill patients has never been evaluated and many clinicians are worried about using no support during the test $[14,15]$.

The aim of our study was thus to assess which weaning test would best reproduce post-extubation inspiratory effort in obese critically ill patients. We compared a T-piece trial to weaning tests with PSV 7 and positive end-expiratory pressure (PEEP) 7 $\mathrm{cmH}_{2} \mathrm{O}$; PSV 0 and PEEP $7 \mathrm{cmH}_{2} \mathrm{O}$; PSV 7 and PEEP $0 \mathrm{cmH}_{2} \mathrm{O}$; PSV 0 and PEEP $0 \mathrm{cmH}_{2} \mathrm{O}$, in this particular population. We hypothesized that the T-tube or PSV 0 and PEEP $0 \mathrm{cmH}_{2} \mathrm{O}$ would best approximate the post-extubation WOB.

\section{Methods}

\section{Study}

This was a physiological prospective randomized crossover study (Additional file 1: Table S1), approved by the
Ethics Committee of the Saint-Eloi Teaching Hospital (2012 A-00294-39, Comité de Protection des Personnes Sud Méditerranée III, Montpellier, France), and registered on clinical trial.gov (reference NCT01616901, registered June 4th, 2012). All patients provided their written informed consent.

\section{Patients}

Upon admission, height and weight were measured using the bed scale and a tape measure. All morbidly obese patients, defined by a body mass index (total body weight in $\mathrm{kg} /$ height in $\mathrm{m}^{2}$ ) $>35 \mathrm{~kg} / \mathrm{m}^{2}$ [16], were considered eligible for inclusion in the study if they were mechanically ventilated for at least $24 \mathrm{~h}$ and were considered by the physician on duty to be ready for extubation. Patients were not included in the study if there was any contraindication to the insertion of an esophageal catheter.

\section{Experimental procedure and study design}

A 15-minute period corresponding to a baseline state was first recorded (using PSV and PEEP set by the clinician in charge of the patient before inclusion). Patients were then randomly assessed using computer-driven software with five settings: PSV 7 and PEEP $7 \mathrm{cmH}_{2} \mathrm{O}$; PSV 0 and PEEP $7 \mathrm{cmH}_{2} \mathrm{O}$; PSV 7 and PEEP $0 \mathrm{cmH}_{2} \mathrm{O}$; PSV 0 and PEEP $0 \mathrm{cmH}_{2} \mathrm{O}$ or the $\mathrm{T}$ piece. Each setting lasted 15 minutes with a 10-minute period of return to baseline steady state between each setting (Fig. 1). Steady state was defined clinically as a period sufficient to ensure clinical stability in respiratory and hemodynamic variables assessed by a physical exam which took into account heart rate, respiratory rate, paradoxical breathing pattern, accessory muscle use, grunting at end expiration and nasal flaring [17], and as previously performed by our group $[18,19]$.

After being explored with these five settings, and in the case of clinical success in the different weaning trials, patients were ventilated for 10 minutes using baseline state variables and then were extubated if the clinical state was judged adequate by the clinician in charge. A postextubation measurement was performed 20 minutes after extubation using an oro-nasal oxygen mask with a flow of $5 \mathrm{~L} /$ minute (equivalent to inspired oxygen fraction $\left(\mathrm{FiO}_{2}\right)$ of 0.4 [20]). According to our local protocol described in detail in a previous review [21], and after having achieved each step of the protocol, non-invasive ventilation was performed as a prophylactic routine measure in the immediate post-extubation period, for between 30 and $45 \mathrm{mi}$ nutes every 4 to $6 \mathrm{~h}$. Settings were adjusted to target the following: tidal volume $\left(\mathrm{V}_{\mathrm{T}}\right) 6-10 \mathrm{ml} / \mathrm{kg}$ of ideal body weight, respiratory rate (RR) $12-20 \mathrm{c} /$ minute and pulse 


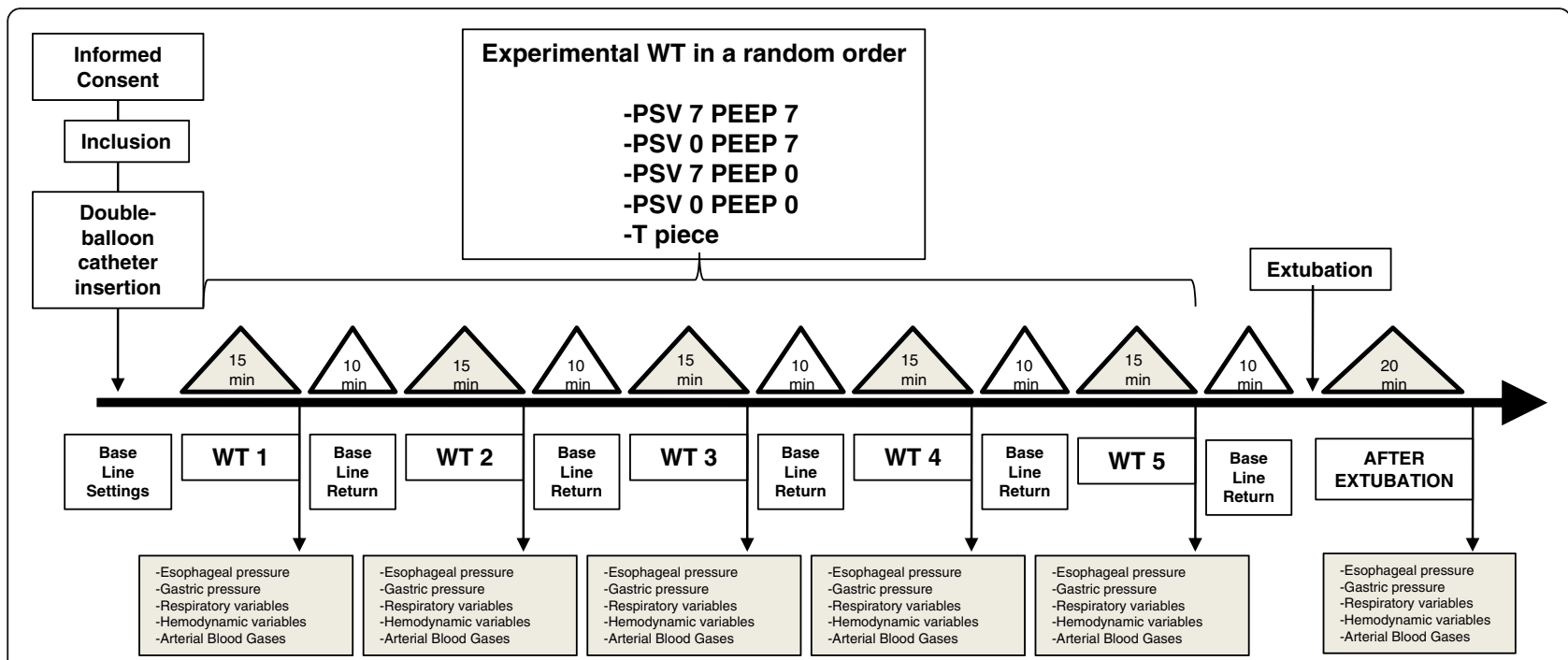

Fig. 1 Study design. Eleven morbidly obese patients ventilated in pressure support ventilation (PSV) and positive end-expiratory pressure (PEEP), considered as baseline settings, were included to randomly perform the five weaning test modalities of the study before extubation: PSV $7 \mathrm{cmH}_{2} \mathrm{O}+$ PEEP $7 \mathrm{~cm} \mathrm{H} \mathrm{H}_{2} \mathrm{O}$; PSV $0 \mathrm{cmH}_{2} \mathrm{O}+$ PEEP $7 \mathrm{cmH}_{2} \mathrm{O}$; PSV $7 \mathrm{cmH}_{2} \mathrm{O}+$ PEEP $0 \mathrm{cmH}_{2} \mathrm{O}$; PSV $0 \mathrm{cmH}_{2} \mathrm{O}+$ PEEP $0 \mathrm{cmH} \mathrm{c}_{2} \mathrm{O}$ or the T piece. All measurements were obtained after 15 minutes of each test. A 10-minute period of return to baseline state (with initial settings of ventilation parameters before the first weaning test) was performed between each test and before extubation. WT weaning test

arterial oxygen saturation (SpO2) equal or above $95 \%$. Non-invasive ventilation was never performed before the end of the protocol.

\section{Measurements}

All patients were studied in a semi-recumbent position with the head of the bed elevated to an angle from 30 to 45 degrees, according to patient comfort. [22] Procedures are detailed in the additional material. Briefly, the respiratory mechanics measurements comprised flow, airway pressure, esophageal (Pes) and gastric (Pga) pressure swings. Trans-diaphragmatic swings (Pdi) were calculated by subtracting Pes from Pga. Minute ventilation (VE), tidal volume $\left(V_{T}\right)$, inspiratory $(\mathrm{Ti})$, expiratory time $(\mathrm{Te})$, total cycle duration (Ttot) and RR were calculated from the numerical integration of the flow signal.

The inspiratory WOB per breath performed by the patient was calculated from a Campbell diagram taking into account the presence of intrinsic PEEP. Eesophageal and trans-diaphragmatic pressure-time products (PTPes and PTPdi) were also measured as previously reported $[23,24]$. Analyses of arterial blood gases were obtained at the end of each test.

\section{Statistical analysis}

All values are presented as mean \pm SD. To assess differences between the weaning tests, we used the Friedman test and then pairwise comparisons with the Wilcoxon test if a significant difference appeared. Statistical analysis was performed by an independent statistician (NM) using R software ${ }^{\circ}$ ( $R$ Foundation for Statistical Computing, Auckland, New Zealand).

Based on the literature review, we hypothesized that the post-extubation WOB would be similar to the T-tube WOB $[25,26]$ and would approximate $1.5+/$ $0.9 \mathrm{~J} / \mathrm{L}$ in obese critically ill patients. We also hypothesized that WOB in PSV $7 \mathrm{cmH}_{2} \mathrm{O}$ and PEEP $7 \mathrm{cmH}_{2} \mathrm{O}$ would approximate $0.7+/-0.5 \mathrm{~J} / \mathrm{L}$ [27]. Then, with an alpha risk at 0.05 and a power at $0.90,12$ patients would be needed. We decided to include 17 patients in order to make sure that 12 patients would complete the study. Significance was set at $p<0.01$ after correction for the number of multiple comparisons, i.e., using the Bonferroni test.

\section{Results \\ Patients}

Between March and December 2012, 40 obese patients with body mass index $\geq 35 \mathrm{~kg} / \mathrm{m}^{2}$ were admitted in our center. Among them, 17 met the inclusion criteria. Sixteen patients (13 women and 3 men) with mean body mass index of $44 \mathrm{~kg} / \mathrm{m}^{2}\left( \pm 8 \mathrm{~kg} / \mathrm{m}^{2}\right)$ were prospectively enrolled in the present study, as shown in Fig. 2. Characteristics of the subjects are detailed in Table 1. Mean duration of invasive mechanical 


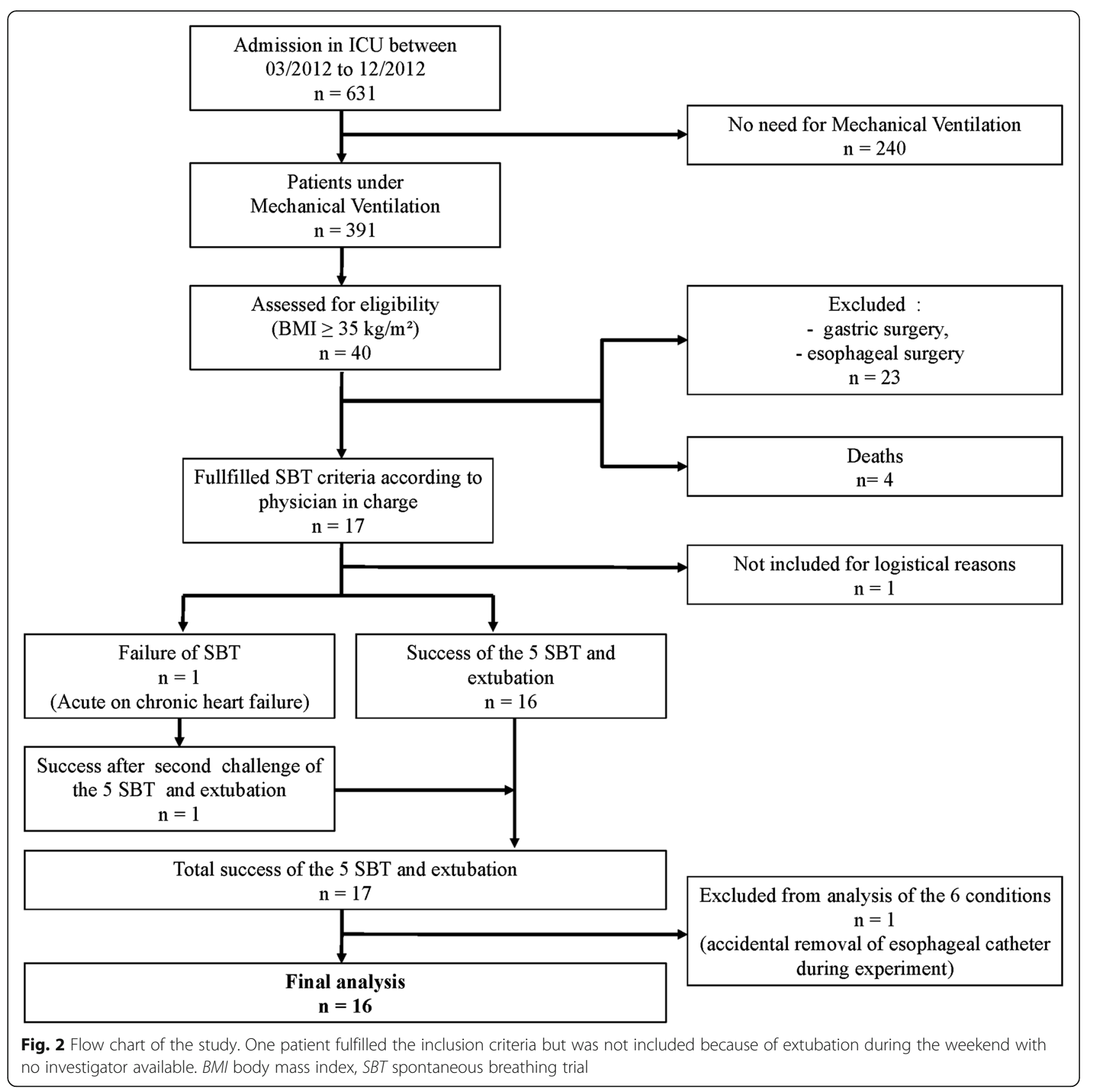

ventilation before enrollment in the study was 6 days ( \pm 7 days). The five weaning tests were well-tolerated by all patients and all of them but one were successfully extubated.

The first patient was initially unable to complete the five weaning tests. She was re-challenged $72 \mathrm{~h}$ later, and succeeded the tests and extubation. Seven days after extubation, she developed cardiorespiratory distress and was re-intubated. Patient number 15 developed hypoxemic acute respiratory failure and was re-intubated $12 \mathrm{~h}$ after extubation. One patient had accidental nasogastric catheter removal after extubation, preventing the measurement of respiratory muscle work variables after extubation. This patient was excluded from the final analysis.

\section{Respiratory variables and gas exchange}

There was no statistical difference in any of the different respiratory variables (shown in Table 2) among the five weaning tests or at 20 minutes after extubation. In particular, differences in the $R R / V_{T}$ ratio were not statistically significant between the five weaning 
Table 1 Characteristics of the patients

\begin{tabular}{|c|c|c|c|c|c|c|c|c|c|c|c|c|c|c|}
\hline $\begin{array}{l}\text { Patient } \\
\text { number }\end{array}$ & Sex & $\begin{array}{l}\text { Age } \\
\text { (years) }\end{array}$ & SAPS ॥ & $\begin{array}{l}\text { Height } \\
(\mathrm{cm})\end{array}$ & $\begin{array}{l}\text { Weight } \\
(\mathrm{kg})\end{array}$ & $\begin{array}{l}\mathrm{BMI} \\
\left(\mathrm{kg} / \mathrm{m}^{2}\right)\end{array}$ & $\begin{array}{l}\text { Underlying } \\
\text { diseases }\end{array}$ & $\begin{array}{l}\text { Etiology of respiratory } \\
\text { failure }\end{array}$ & $\begin{array}{l}\text { ETT ID } \\
(\mathrm{mm}) \\
\end{array}$ & $\begin{array}{l}\text { MV before } \\
\text { extubation } \\
\text { (days) }\end{array}$ & $\begin{array}{l}\text { PSV at } \\
\text { baseline } \\
\left(\mathrm{cmH}_{2} \mathrm{O}\right)\end{array}$ & $\begin{array}{l}\text { PEEP at } \\
\text { baseline } \\
\left(\mathrm{cmH}_{2} \mathrm{O}\right)\end{array}$ & $\begin{array}{l}\text { Extubation } \\
\text { failure } \\
(\mathrm{Y} / \mathrm{N})\end{array}$ & $\begin{array}{l}\text { Outcome } \\
\text { (D/S) }\end{array}$ \\
\hline 1 & $\mathrm{~F}$ & 83 & 109 & 150 & 80 & 35 & CHF & Small bowel ischemia & 7.5 & 7 & 8 & 6 & $\mathrm{~N}$ & D \\
\hline 2 & $\mathrm{~F}$ & 85 & 68 & 163 & 115 & 43 & NIDDM & Pneumonia & 7.5 & 4 & 15 & 7 & $\mathrm{~N}$ & $S$ \\
\hline 3 & M & 64 & 50 & 170 & 130 & 44 & NIDDM & Acute pancreatitis & 8 & 3 & 12 & 8 & N & S \\
\hline 4 & $\mathrm{~F}$ & 59 & 60 & 155 & 95 & 39 & None & Peritonitis & 7.5 & 3 & 12 & 8 & $\mathrm{~N}$ & $\mathrm{~s}$ \\
\hline 5 & $\mathrm{~F}$ & 49 & 66 & 160 & 174 & 67 & COPD, OSA & Septic shock & 7.5 & 6 & 10 & 10 & $\mathrm{~N}$ & S \\
\hline 6 & $\mathrm{~F}$ & 25 & 29 & 172 & 145 & 49 & None & Asthma & 7.5 & 1 & 10 & 8 & $\mathrm{~N}$ & S \\
\hline 7 & $\mathrm{~F}$ & 54 & 19 & 153 & 121 & 51 & Asthma, HTN & Post abdominal surgery & 7.5 & 1 & 10 & 8 & $\mathrm{~N}$ & S \\
\hline 8 & M & 37 & 54 & 180 & 130 & 40 & None & Acute pancreatitis & 8 & 14 & 8 & 10 & N & S \\
\hline 9 & $\mathrm{~F}$ & 78 & 90 & 155 & 87 & 36 & None & Bowel obstruction & 7.5 & 4 & 8 & 5 & N & S \\
\hline 10 & $\mathrm{~F}$ & 49 & 78 & 167 & 112 & 41 & Asthma, OSA & Peritonitis & 7.5 & 30 & 8 & 5 & $\mathrm{~N}$ & $S$ \\
\hline 11 & $\mathrm{~F}$ & 73 & 77 & 150 & 93 & 41 & $\mathrm{CHF}, \mathrm{AF}$ & Septic shock & 7.5 & 4 & 12 & 6 & N & D \\
\hline 12 & $\mathrm{~F}$ & 50 & 45 & 162 & 94 & 36 & None & Necrotizing fasciitis & 7.5 & 2 & 9 & 7 & $\mathrm{~N}$ & S \\
\hline 13 & M & 63 & 64 & 175 & 180 & 56 & NIDDM, HTN & Small bowel bleeding & 7.5 & 1 & 8 & 10 & $\mathrm{~N}$ & S \\
\hline 14 & $\mathrm{~F}$ & 43 & 48 & 155 & 105 & 43 & OSA, home ventilation & Pneumonia & 7.5 & 3 & 12 & 7 & N & S \\
\hline 15 & $\mathrm{~F}$ & 77 & 41 & 155 & 84 & 36 & NIDDM, HTN & Pancreatitis & 7.5 & 7 & 9 & 7 & Y & $S$ \\
\hline 16 & $\mathrm{~F}$ & 50 & 64 & 164 & 124 & 46 & OSA, home ventilation & Post abdominal surgery & 7.5 & 8 & 14 & 8 & $\mathrm{~N}$ & S \\
\hline Mean & & 59 & 60 & 162 & 117 & 44 & & & & 6 & 10 & 7 & & \\
\hline SD & & 17 & 22 & 9 & 30 & 8 & & & & 7 & 2 & 2 & & \\
\hline
\end{tabular}

Abbreviations: AF atrial fibrillation, BMI body mass index; CHF chronic heart failure, $D$ deceased; ETT ID endotracheal tube internal diameter; $F$ female; $M$ male; $H T N$ hypertension, mechanical ventilation; NIDDM noninsulin-dependent diabetes mellitus; OSA obstructive sleep apnoea, PEEP positive end-expiratory pressure; PSV pressure support ventilation; SAPS II Simplified Acute Physiology Score II [34]; S survived 
Table 2 Respiratory variables during the five different weaning tests and 20 minutes after extubation

\begin{tabular}{|c|c|c|c|c|c|c|}
\hline & PSV & PSV & PSV & PSV & T piece & After extubation \\
\hline & $+7 \mathrm{cmH}_{2} \mathrm{O}$ PEEP & $0 \mathrm{cmH}_{2} \mathrm{O}$ PEEP & $+7 \mathrm{cmH}_{2} \mathrm{O}$ PEEP & $0 \mathrm{cmH}_{2} \mathrm{O}$ PEEP & & \\
\hline & $+7 \mathrm{cmH}_{2} \mathrm{O}$ & $+7 \mathrm{cmH}_{2} \mathrm{O}$ & $\mathrm{O} \mathrm{cmH}_{2} \mathrm{O}$ & $\mathrm{O} \mathrm{CmH}_{2} \mathrm{O}$ & & \\
\hline $\mathrm{Ti}, \mathrm{s}$ & $0.90 \pm 0.2$ & $0.93 \pm 0.23$ & $0.82 \pm 0.24$ & $0.84 \pm 0.28$ & $0.81 \pm 0.3$ & $0.89 \pm 0.43$ \\
\hline Ttot, s & $2.6 \pm 0.8$ & $2.4 \pm 0.6$ & $2.2 \pm 0.6$ & $2.1 \pm 0.6$ & $2.1 \pm 0.6$ & $2.2 \pm 0.8$ \\
\hline $\mathrm{Ti} / \mathrm{Tt}$ tot, $\%$ & $35.7 \pm 3.6$ & $38.7 \pm 4.2$ & $37.8 \pm 4.2$ & $39.3 \pm 4.4$ & $38.7 \pm 4.7$ & $40.8 \pm 4.3$ \\
\hline$V_{T}, L$ & $0.43 \pm 0.12$ & $0.41 \pm 0.1$ & $0.38 \pm 0.1$ & $0.37 \pm 0.1$ & $0.35 \pm 0.1$ & $0.36 \pm 0.1$ \\
\hline $\mathrm{RR}$, breaths/minute & $25 \pm 6$ & $26 \pm 7$ & $29 \pm 6$ & $30 \pm 8$ & $31 \pm 7$ & $30 \pm 8$ \\
\hline $\mathrm{RR}_{\mathrm{T}}$, minutes $/ \mathrm{mL}$ & $64.5 \pm 26.8$ & $69.7 \pm 25.0$ & $83.1 \pm 34.4$ & $87.8 \pm 36.4$ & $94.7 \pm 38.1$ & $88.6 \pm 34$ \\
\hline$V E, L / m i n u t e$ & $10.3 \pm 2.4$ & $10.41 \pm 2.9$ & $10.8 \pm 2.6$ & $10.8 \pm 3.3$ & $10.5 \pm 3.2$ & $11.2 \pm 4.4$ \\
\hline PEEPi, $\mathrm{cmH}_{2} \mathrm{O}$ & $1.1 \pm 0.9$ & $1.7 \pm 1.2$ & $2.5 \pm 2.3$ & $2.6 \pm 2.2$ & $2.4 \pm 2.6$ & $2.2 \pm 2.3$ \\
\hline
\end{tabular}

There were no statistically significant differences between respiratory variables among the successive tests. Abbreviations: PSV pressure support ventilation; PEEP positive end-expiratory pressure; $P E E P i$ intrinsic positive end-expiratory pressure; $R R$ respiratory rate; $T i$ inspiratory time; Ttot total respiratory time; $V E$ volume per minute; $V_{T}$ tidal volume

tests or at 20 minutes after extubation. There was no statistically significant difference in arterial blood gases or hemodynamic variables among the six steps of the study, as shown in Table 3.

\section{Inspiratory effort}

Figures 3, 4, and 5 show the individual and mean values of the main variables studied, and representative tracings of Pes, Pga and Pdi can be seen in Fig. 6 . There was a significant difference in all respiratory effort variables (swings of Pes and Pdi, PTPes and PTPdi, WOB in $\mathrm{J} / \mathrm{L}$ and in $\mathrm{J} / \mathrm{min}$ ) between the weaning tests and after the extubation period $(p<0.001)$ (Table 4). Weaning tests performed with positive pressure constantly overestimated post-extubation inspiratory effort. Inspiratory effort measured with either the $\mathrm{T}$ tube or PSV $0+$ PEEP $0 \mathrm{cmH}_{2} \mathrm{O}$ was not different to post-extubation inspiratory effort. We then identified both PSV $0+$ PEEP $0 \mathrm{cmH}_{2} \mathrm{O}$ and the
T-piece trial as the weaning tests that reproduce post-extubation inspiratory effort and the WOB (Additional files 2, 3, 4, 5, 6 and 7).

\section{Discussion}

To our knowledge, this is the first physiological study that specifically investigates the inspiratory effort during weaning of mechanical ventilation in a population of critically ill morbidly obese patients. The main result of this study is that for obese patients, the $\mathrm{T}$ piece and PSV $0+$ PEEP $0 \mathrm{cmH}_{2} \mathrm{O}$ weaning tests are the tests that best predict post-extubation inspiratory effort and WOB.

Because of a lack of consensus on the best test to use before extubation in this population, we aimed to determine which one reflects the breathing effort after extubation. Some authors described extubation of obese patients after a 30-minute period of CPAP 5 $\mathrm{cmH}_{2} \mathrm{O}$ [14], others after a trial of $\mathrm{FiO}_{2} \quad 100 \%$

Table 3 Arterial blood gases and hemodynamic variables during the five different weaning tests and at 20 minutes after extubation

\begin{tabular}{|c|c|c|c|c|c|c|}
\hline & PSV & PSV & PSV & PSV & T piece & After extubation \\
\hline & $+7 \mathrm{cmH}_{2} \mathrm{O}$ PEEP & $\mathrm{O} \mathrm{cmH}_{2} \mathrm{O}$ PEEP & $+7 \mathrm{cmH}_{2} \mathrm{O}$ PEEP & $\mathrm{O} \mathrm{cmH}_{2} \mathrm{O}$ PEEP & & \\
\hline & $+7 \mathrm{cmH}_{2} \mathrm{O}$ & $+7 \mathrm{cmH}_{2} \mathrm{O}$ & $\mathrm{O} \mathrm{cmH}_{2} \mathrm{O}$ & $\mathrm{O} \mathrm{cmH}_{2} \mathrm{O}$ & & \\
\hline $\mathrm{Ph}$ & $7.45 \pm 0.06$ & $7.44 \pm 0.06$ & $7.44 \pm 0.06$ & $7.44 \pm 0.06$ & $7.43 \pm 0.06$ & $7.42 \pm 0.06$ \\
\hline $\mathrm{Pa}_{\mathrm{CO} 2}, \mathrm{mmHg}$ & $41 \pm 11$ & $42 \pm 11$ & $43 \pm 12$ & $43 \pm 12$ & $44 \pm 13$ & $44 \pm 10$ \\
\hline $\mathrm{Pa}_{\mathrm{O} 2} / \mathrm{Fl}_{\mathrm{O} 2}$ & $277 \pm 76$ & $257 \pm 81$ & $252 \pm 73$ & $230 \pm 65$ & $217 \pm 65$ & $224 \pm 51$ \\
\hline $\mathrm{SBP}, \mathrm{mmHg}$ & $148 \pm 22$ & $148 \pm 26$ & $148 \pm 26$ & $146 \pm 30$ & $150 \pm 18$ & $147 \pm 24$ \\
\hline $\mathrm{DBP}, \mathrm{mmHg}$ & $72 \pm 12$ & $71 \pm 12$ & $73 \pm 12$ & $72 \pm 15$ & $69 \pm 13$ & $70 \pm 15$ \\
\hline $\mathrm{HR}$, beats/minute & $96 \pm 14$ & $97 \pm 16$ & $98 \pm 16$ & $100 \pm 16$ & $99 \pm 14$ & $101 \pm 15$ \\
\hline
\end{tabular}

There were no statistically significant differences between respiratory variables among the successive tests. Abbreviations: $D B P$ diastolic blood pressure, $H R$ heart rate, ND not done, PEEP positive end-expiratory pressure, PSV pressure support ventilation, SBP systolic blood pressure 

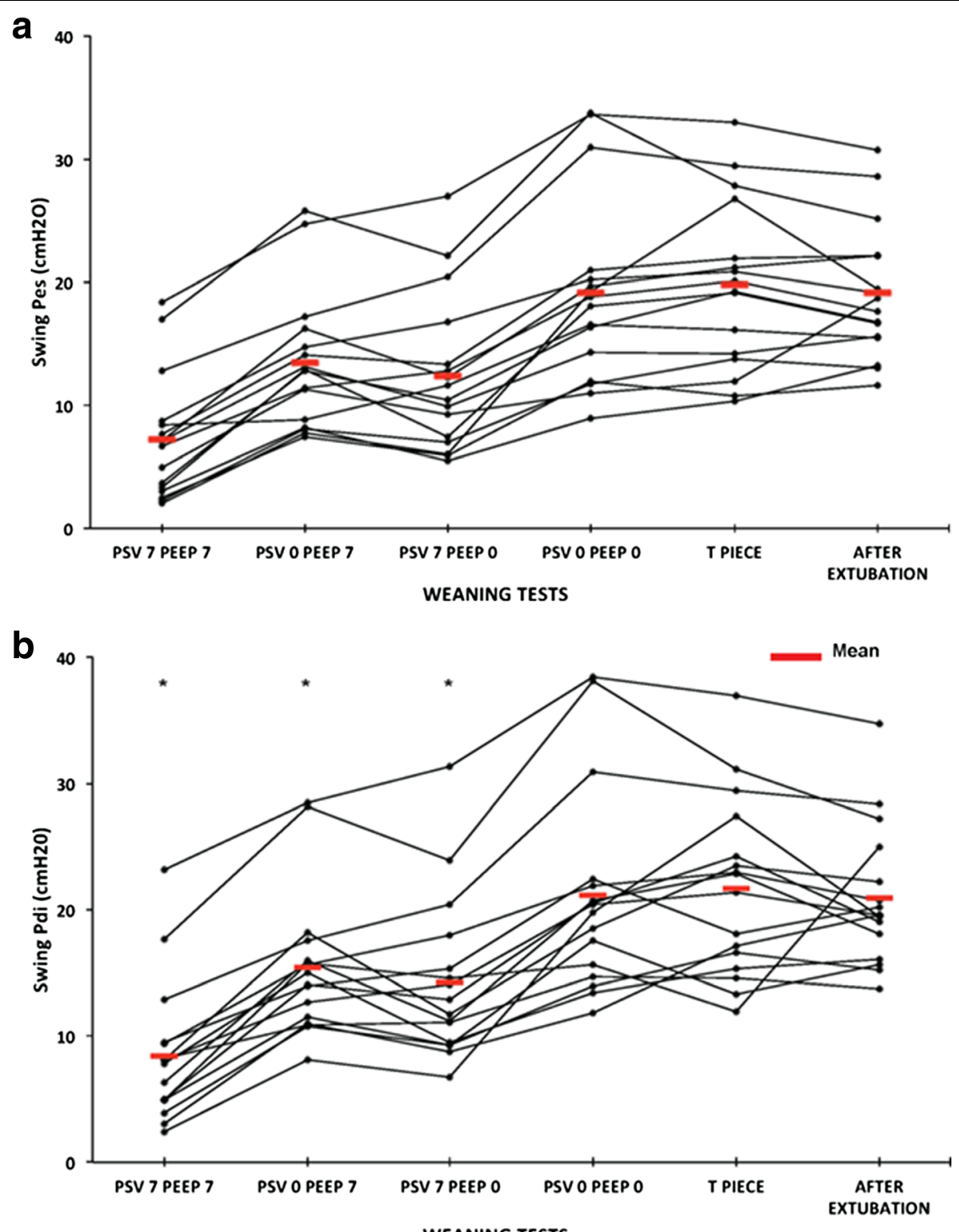

Fig. 3 Esophageal (a) and trans-diaphragmatic (b) swings. Individual and mean changes in esophageal and trans-diaphragmatic swings during the five weaning tests and 20 minutes after extubation. All the tests show that the weaning tests that best reproduce respiratory muscle work after extubation were pressure support ventilation (PSV) $0 \mathrm{cmH}_{2} \mathrm{O}$ + positive end-expiratory pressure (PEEP) $0 \mathrm{cmH}_{2} \mathrm{O}$ and the T piece, with no statistically significant difference between the two. ${ }^{*} p<0.001$ when compared with after extubation. Pdi transdiaphragmatic pressure, pes esophageal pressure

combined with a CPAP of $10 \mathrm{cmH}_{2} \mathrm{O}$. [15] An ongoing multicenter observational study in France (FREEREA study), will provide some epidemiological data about weaning and extubation in this particular population. The preliminary results (unpublished) show that among 64 critically ill morbidly obese patients extubated, $22(34 \%)$ were extubated after a T tube, 28 (44\%) after a low PSV trial, 12 (19\%) with no spontaneous breathing trial and 2 (3\%) after a different weaning trial. These data justify our study as there is wide heterogeneity of extubation practice in this population, with a high proportion of patients being extubated from a substantial level of support.

Our study presents limitations. First, we investigated the inspiratory effort indexes twenty minutes after extubation and the study was not designed to explore long-term consequences of several weaning tests on oxygenation, endexpiratory lung volume or outcome. Because outcome 


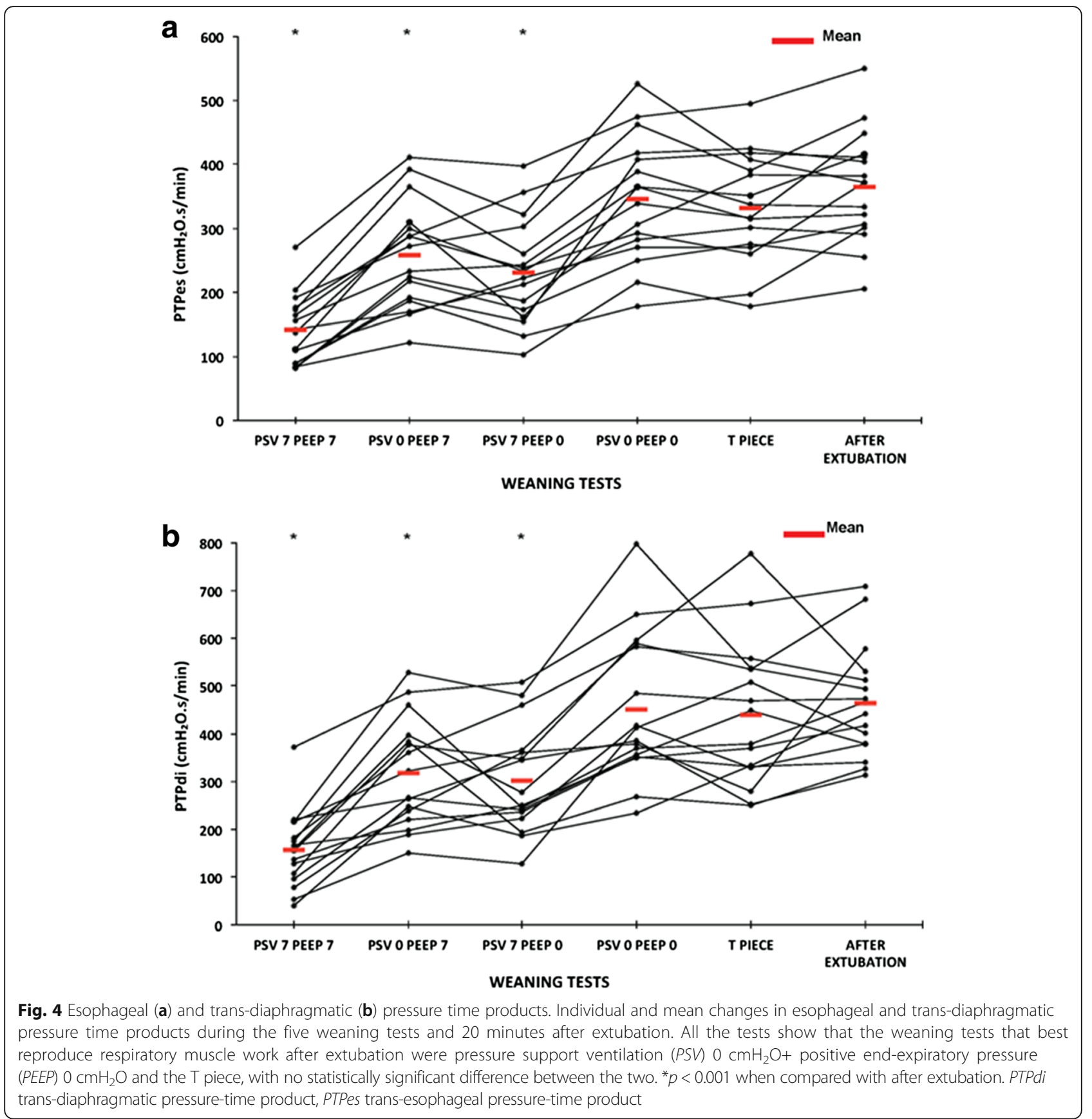

was not a study endpoint, we cannot make any final recommendation about which weaning test is associated with the highest rate of weaning success. Ideally, a weaning test would perfectly predict the ability of the patient to breathe alone and without being ventilatory assisted by simulating the post-extubation respiratory constraint [26]. Second, post-extubation intermittent non-invasive ventilation is routinely used in our unit for high-risk patients $[14,21]$ to rest the inspiratory muscles and improve lung aeration. It may have contributed to our low rate of reintubation $(6 \%)$.
The present study focused on morbidly obese patients and found results consistent with the studies published by Straus et al. [25] and Cabello et al. [8], which included non-obese patients. We report that the $\mathrm{T}$ piece and PSV $0+$ PEEP $0 \mathrm{cmH}_{2} \mathrm{O}$ weaning tests were the two tests that best approximated the WOB after extubation. We also found that the PSV $7+$ PEEP $0 \mathrm{cmH}_{2} \mathrm{O}$ test leads to a major underestimation of the WOB after extubation in obese patients with significantly less inspiratory effort in comparison with both the $\mathrm{T}$ piece test and 20 minutes after extubation. Straus et al demonstrated 

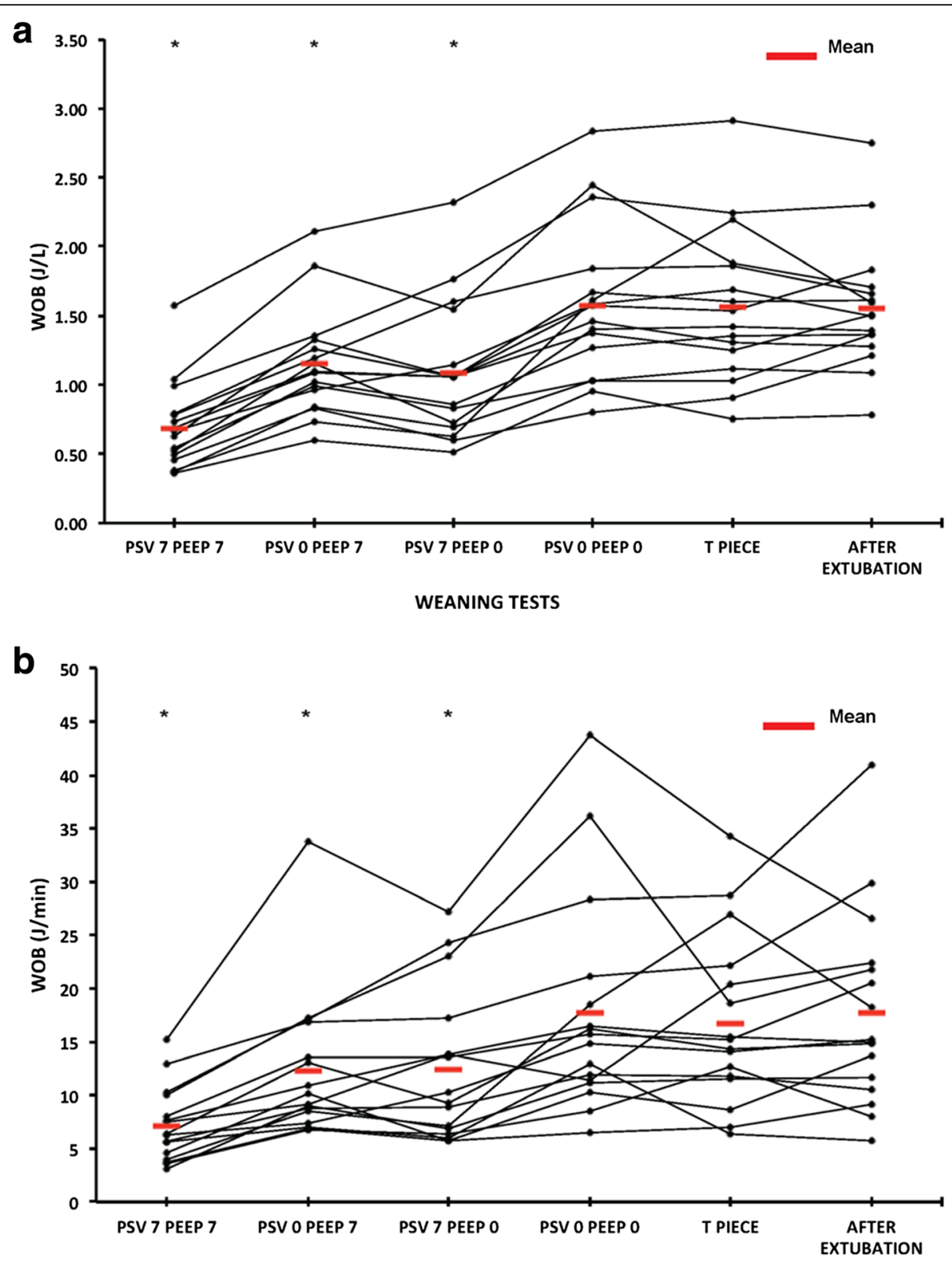

WEANING TESTS

Fig. 5 Work of breathing (WOB) in $\mathrm{J} / \mathrm{L}$ (a) and in $\mathrm{J} /$ minute (b). Individual and mean changes in the WOB during the five weaning tests and 20 minutes after extubation. All the tests show that the weaning tests that best reproduced respiratory muscle work after extubation were pressure support ventilation (PSV) $0 \mathrm{cmH}_{2} \mathrm{O} \mathrm{cmH}_{2} \mathrm{O}$ + positive end-expiratory pressure (PEEP) $0 \mathrm{cmH}_{2} \mathrm{O}$ and the T piece, with no statistically significant difference between the two. ${ }^{*} p<0.001$ when compared with after extubation

that post-extubation $\mathrm{WOB}$ was well-approximated by the WOB during a T-piece test and that the endotracheal tube was responsible for about $11 \%$ of the total work of breathing. [25] More recently, Cabello et al. compared a spontaneous breathing trial on a T-piece with low PSV $\left(7 \mathrm{~cm} \mathrm{H} \mathrm{H}_{2} \mathrm{O}\right)$ with or without PEEP in a subpopulation of patients with heart failure who were difficult to wean. [8] The authors concluded that performing the weaning test while maintaining a positive pressure in the circuit underestimates the postextubation WOB and unmasks a possible effect on left ventricular function, and suggested the $\mathrm{T}$ piece as the weaning test of choice in these patients.

In a landmark physiological study, Brochard et al. demonstrated that breathing through the $\mathrm{T}$ piece overestimates the WOB by $27 \pm 18 \%$ compared to the postextubation period [26]. Contrary to the present study, Brochard et al. included a high proportion of patients 


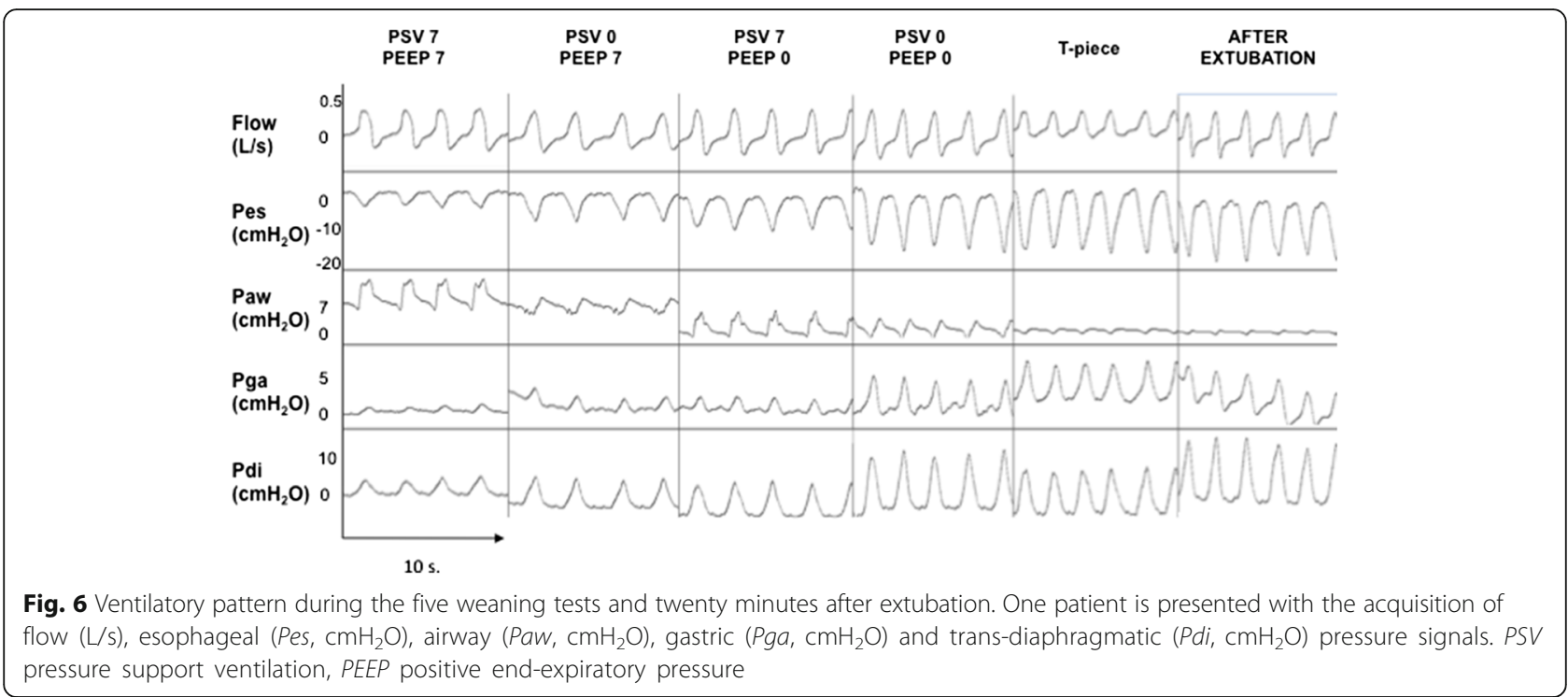

with chronic obstructive pulmonary disease, and used ventilators with higher ventilatory circuit-resistive load [28] and lower pressurization performance, especially in terms of inspiratory-trigger-imposed WOB [29, 30].

As compared to the literature on non-obese patients, WOB values evaluated in the present study were higher $[26,31]$. In morbidly obese patients, an elevation of pharyngeal collapsibility and upper airway resistance related to fatty deposits on pharynx and oral soft tissue and associated with local inflammation can increase the WOB [32]. Weaning trials performed with positive pressure underestimated post-extubation WOB by $33 \%(0.5 \mathrm{~J} / \mathrm{L})$ up to $50 \%(0.8 \mathrm{~J} / \mathrm{L})$ according to the ventilator setting. An increase of $0.5-0.8 \mathrm{~J} /$ $\mathrm{L}$ represents a significant additional workload, as WOB in healthy subjects during quiet breathing is about $0.35-0.5 \mathrm{~J} / \mathrm{L}$ [33, 34]. Furthermore, WOB $\geq 0.8 \mathrm{~J} / \mathrm{L}$ has been reported as being associated with weaning failure [35]. Extubating an obese patient after having performed a weaning test without positive pressure could lead to early onset atelectasis if the patient was unable to control for end-expiratory lung volume without PEEP.

\section{Conclusions}

For the first time the present study reports new insights into respiratory physiology in morbidly obese critically ill candidates to be weaned from the ventilator. These data may be useful for clinicians managing these challenging patients and help make difficult decisions about extubation. We report that either a $\mathrm{T}$ piece or a PSV 0 and PEEP $0 \mathrm{cmH}_{2} \mathrm{O}$ test are the trials that predict post-extubation work of breathing in morbidly obese patients. The consequences on midterm oxygenation and lung aeration, and on the weaning success rate of such weaning tests were, however, not studied.

Table 4 Inspiratory muscle effort during the five different weaning tests and 20 minutes after extubation

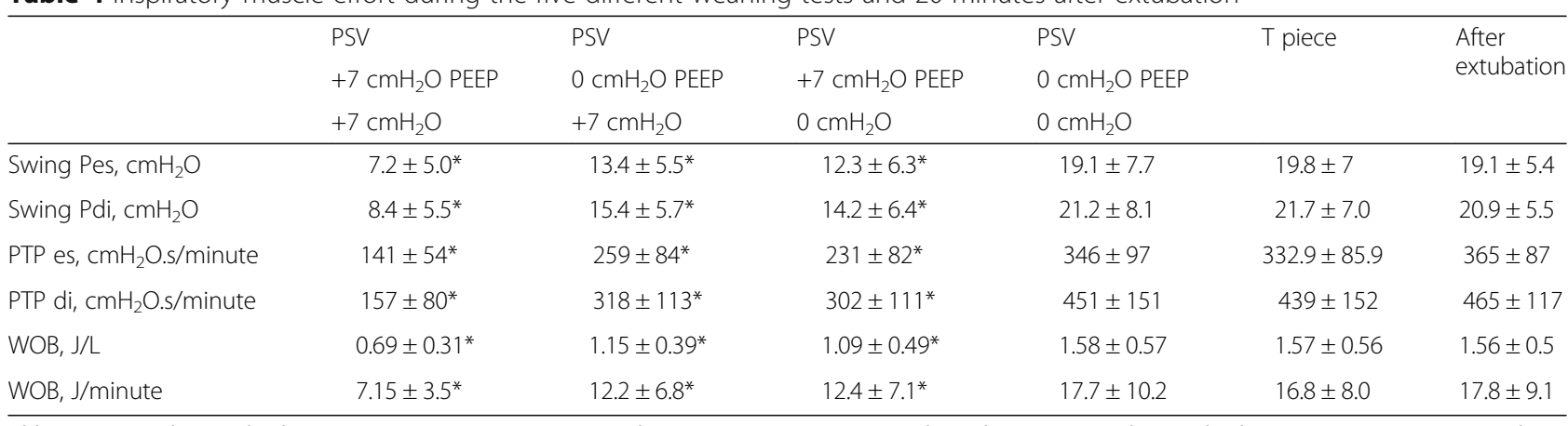

Abbreviations: Pdi trans-diaphragmatic pressure, PEEP positive end-expiratory pressure, Pes esophageal pressure, PTPdi trans-diaphragmatic pressure time product, PTPes esophageal pressure time product, PSV pressure support ventilation, WOB work of breathing. ${ }^{*} p<0.001$ when compared with after extubation 


\section{Additional files}

Additional file 1: Supplementary material. (DOCX $44 \mathrm{~kb}$ )

Additional file 2: Figure S1. difference in esophageal pressure between each test and the post-extubation period. Dashed line represents the absence of difference between the test and the post-extubation period. (JPG $44 \mathrm{~kb}$ )

Additional file 3: Figure S2. difference in the trans-diaphragmatic pressure between each test and the post-extubation period. Dashed line represents the absence of difference between the test and the postextubation period. (JPG $48 \mathrm{~kb}$ )

Additional file 4: Figure S3. difference in the esophageal pressure time product between each test and the post-extubation period. Dashed line represents the absence of difference between the test and the postextubation period. (JPG $49 \mathrm{~kb}$ )

Additional file 5: Figure S4. difference in the trans-diaphragmatic pressure time product between each test and the post-extubation period. Dashed line represents the absence of difference between the test and the post-extubation period. (JPG $47 \mathrm{~kb}$ )

Additional file 6: Figure S5. difference in the work of breathing expressed in $\mathrm{J} / \mathrm{l}$ between each test and the post-extubation period. Dashed line represents the absence of difference between the test and the post-extubation period. (JPG $44 \mathrm{~kb}$ )

Additional file 7: Figure S6. difference in the work of breathing expressed in $\mathrm{J} / \mathrm{min}$ between each test and the post-extubation period. Dashed line represents the absence of difference between the test and the post-extubation period. (JPG $44 \mathrm{~kb}$ )

\section{Abbreviations}

BMl: Body mass index; CPAP: Continuous positive airway pressure; $\mathrm{FiO}_{2}$ : Inspired oxygen fraction; ICU: Intensive Care Unit; Pdi: Transdiaphragmatic pressure; PEEP: Positive end-expiration pressure; Pes: Esophageal pressure; Pga: Gastric pressure; PSV: Pressure support ventilation; PTPdi: Trans-diaphragmatic pressure-time product; PTPes: Trans-esophageal pressure-time product; RR: Respiratory rate; SBT: Spontaneous breathing trial; $\mathrm{SpO}_{2}$ : Pulse arterial oxygen saturation; Te: Expiratory time; Ti: Inspiratory time; Ttot: Total cycle duration; VE: Minute ventilation; $\mathrm{V}_{\mathrm{T}}$ : Tidal volume; WOB: Work of breathing

\section{Acknowledgements}

We thank Albert Prades, Research Nurse, MSc, Department of Critical Care Medicine and Anesthesiology, Saint Eloi Teaching Hospital, Montpellier, France for his help conducting research in this topic.

\section{Funding}

Departmental resources funded the present study.

\section{Availability of data and materials}

The data that support the findings of this study are available from the corresponding author upon reasonable request.

\section{Authors' contributions}

MM and BJ contributed equally to this work. MM performed the study, analyzed the data and wrote the manuscript. BJ participated in the study design and wrote the manuscript. FG analyzed the data and made critical manuscript revisions. RV analyzed the data and made critical manuscript revisions. YC helped in designing the study, enrolled patients, analyzed the data and made critical manuscript revisions. NM and AJ performed the statistical analysis and made critical manuscript revisions. SM helped in designing the study and extensively corrected the manuscript. GC helped in designing the study and extensively corrected the manuscript. SJ designed the study, analyzed the data and made critical manuscript revisions. LB analyzed the data and made critical manuscript revisions. All authors read and approved the final manuscript.

\section{Competing interests}

Martin Mahul has nothing to disclose; Boris Jung reports personal fees from Merck (Whitehouse station, NJ) and Astellas (Tokyo, Japan) unrelated to the present study; Fabrice Gallia has nothing to disclose; Nicolas Molinari has nothing to disclose; Audrey De Jong has nothing to disclose; Yannaël Coisel has nothing to disclose; Rosanna Vaschetto has nothing to disclose; Stefan Matecki has nothing to disclose; Gerald Chanques has nothing to disclose; Laurent Brochard reports a research contract with Draeger, General Electric and Covidien and honorarium from Draeger unrelated to the present study; Samir Jaber reports personal fees from Maquet, Draeger, Hamilton Medical, Fisher Paykel and Abbott unrelated to the present study.

\section{Consent for publication}

Not applicable.

\section{Ethics approval and consent to participate}

The present study was approved by the Ethics Committee of the Montpellier Teaching Hospital (2012 A-00294-39, Comité de Protection des Personnes Sud Méditerranée III, Montpellier, France), and registered on clinical trial.gov (reference NCT01616901). All patients provided their written informed consent.

\section{Author details}

${ }^{1}$ Intensive Care Unit, Anaesthesia and Critical Care Department, Saint Eloi Teaching Hospital, Centre Hospitalier Universitaire Montpellier, 80 avenue Augustin Fliche, F-34295 Montpellier, Cedex 5, France. ${ }^{2}$ Department of Statistics, University of Montpellier Lapeyronie Hospital, UMR 729 MISTEA, Montpellier, France. ${ }^{3}$ Anaesthesia and Intensive Care Medicine, Maggiore della Carità Hospital, Novara, Italy. ${ }^{4}$ Centre National de la Recherche Scientifique (CNRS 9214) - Institut National de la Santé et de la Recherche Médicale (INSERM U-1046), Montpellier University, Montpellier, France. ${ }^{5}$ Keenan Research Centre, St Michael's Hospital, Toronto, Canada. ${ }^{6}$ Interdepartmental Division of Critical Care Medicine, University of Toronto, Toronto, Canada.

Received: 19 April 2016 Accepted: 16 August 2016

Published online: 27 October 2016

\section{References}

1. Sellares J, Ferrer M, Cano E, Loureiro H, Valencia M, Torres A. Predictors of prolonged weaning and survival during ventilator weaning in a respiratory ICU. Intensive Care Med. 2011;37:775-84.

2. Brochard L, Rauss A, Benito S, Conti G, Mancebo J, Rekik N, et al. Comparison of three methods of gradual withdrawal from ventilatory support during weaning from mechanical ventilation. Am J Respir Crit Care Med. 1994;150:896-903.

3. Boles JM, Bion J, Connors A, Herridge M, Marsh B, Melot C, et al. Weaning from mechanical ventilation. Eur Respir J. 2007;29:1033-56.

4. Thille AW, Richard J-CM, Brochard L. The decision to extubate in the intensive care unit. Am J Respir Crit Care Med. 2013;187:1294-302.

5. Jubran A, Grant BJB, Laghi F, Parthasarathy S, Tobin MJ. Weaning prediction: esophageal pressure monitoring complements readiness testing. Am J Respir Crit Care Med. 2005;171:1252-9.

6. MacIntyre NR, Cook DJ, Ely Jr EW, Epstein SK, Fink JB, Heffner JE, et al. Evidence-based guidelines for weaning and discontinuing ventilatory support: a collective task force facilitated by the American College of Chest Physicians; the American Association for Respiratory Care; and the American College of Critical Care Medicine. Chest. 2001;120:375S-95.

7. McConville JF, Kress JP. Weaning patients from the ventilator. New England J Med. 2012:367:2233-9.

8. Cabello B, Thille AW, Roche-Campo F, Brochard L, Gómez FJ, Mancebo J. Physiological comparison of three spontaneous breathing trials in difficultto-wean patients. Intensive Care Med. 2010;36:1171-9.

9. Tobin MJ. Extubation and the myth of "minimal ventilator settings". Am J Respir Crit Care Med. 2012;185:349-50.

10. Jones RL, Nzekwu M-MU. The effects of body mass index on lung volumes. Chest. 2006;130:827-33.

11. Kress JP, Pohlman AS, Alverdy J, Hall JB. The impact of morbid obesity on oxygen cost of breathing (VO(2RESP)) at rest. Am J Respir Crit Care Med. 1999;160:883-6

12. Littleton SW. Impact of obesity on respiratory function. Respirology. 2012;17: 43-9.

13. Salome CM, King GG, Berend N. Physiology of obesity and effects on lung function. J Appl Physiol. 2010;108:206-11. 
14. El-Solh AA, Aquilina A, Pineda L, Dhanvantri V, Grant B, Bouquin P. Noninvasive ventilation for prevention of post-extubation respiratory failure in obese patients. Eur Respir J. 2006;28:588-95.

15. Zoremba M, Kalmus G, Begemann D, Eberhart L, Zoremba N, Wulf H, et al. Short term non-invasive ventilation post-surgery improves arterial bloodgases in obese subjects compared to supplemental oxygen delivery - a randomized controlled trial. BMC Anesthesiol. 2011;11:10.

16. Clinical guidelines on the identification, evaluation, and treatment of overweight and obesity in adults-the evidence report. national institutes of health. Obes Res. 1998;6 Suppl 2:51S-209S.

17. Persichini R, Gay F, Schmidt M, Mayaux J, Demoule A, Morélot-Panzini C, et al. Diagnostic accuracy of respiratory distress observation scales as surrogates of dyspnea self-report in intensive care unit patients. Anesthesiology. 2015;123:830-7.

18. Coisel Y, Chanques G, Jung B, Constantin J-M, Capdevila X, Matecki S, et al. Neurally adjusted ventilatory assist in critically ill postoperative patients: a crossover randomized study. Anesthesiology. 2010;113:925-35.

19. Clavieras N, Wysocki M, Coisel Y, Galia F, Conseil M, Chanques G, et al. Prospective randomized crossover study of a new closed-loop control system versus pressure support during weaning from mechanical ventilation. Anesthesiology. 2013;119:631-41.

20. Baillard C, Fosse J-P, Sebbane M, Chanques G, Vincent $F$, Courouble $P$, et al. Noninvasive ventilation improves preoxygenation before intubation of hypoxic patients. Am J Respir Crit Care Med. 2006;174:171-7.

21. Jaber S, Chanques G, Jung B. Postoperative noninvasive ventilation. Anesthesiology. 2010;112:453-61.

22. Deye N, Lellouche F, Maggiore SM, Taillé S, Demoule A, L'Her E, et al. The semi-seated position slightly reduces the effort to breathe during difficult weaning. Intensive Care Med. 2013;39:85-92.

23. Jaber S, Carlucci A, Boussarsar M, Fodil R, Pigeot J, Maggiore S, et al. Helium-oxygen in the postextubation period decreases inspiratory effort. Am J Respir Crit Care Med. 2001;164:633-7.

24. Sassoon CS, Light RW, Lodia R, Sieck GC, Mahutte CK. Pressure-time product during continuous positive airway pressure, pressure support ventilation, and T-piece during weaning from mechanical ventilation. Am Rev Respir Dis. 1991;143:469-75

25. Straus C, Louis B, Isabey D, Lemaire F, Harf A, Brochard L. Contribution of the endotracheal tube and the upper airway to breathing workload. Am J Respir Crit Care Med. 1998:157:23-30.

26. Brochard L, Rua F, Lorino H, Lemaire F, Harf A. Inspiratory pressure support compensates for the additional work of breathing caused by the endotracheal tube. Anesthesiology. 1991;75:739-45.

27. Mehta S, Nelson DL, Klinger JR, Buczko GB, Levy MM. Prediction of postextubation work of breathing. Crit Care Med. 2000:28:1341-6.

28. Lyazidi A, Thille AW, Carteaux G, Galia F, Brochard L, Richard J-CM. Bench test evaluation of volume delivered by modern ICU ventilators during volume-controlled ventilation. Intensive Care Med. 2010;36:2074-80.

29. Jaber S, Tassaux D, Sebbane M, Pouzeratte Y, Battisti A, Capdevila X, et al. Performance characteristics of five new anesthesia ventilators and four intensive care ventilators in pressure-support mode: a comparative bench study. Anesthesiology. 2006;105:944-52.

30. Thille AW, Lyazidi A, Richard J-CM, Galia F, Brochard L. A bench study of intensive-care-unit ventilators: new versus old and turbine-based versus compressed gas-based ventilators. Intensive Care Med. 2009;35:1368-76.

31. Nathan SD, Ishaaya AM, Koerner SK, Belman MJ. Prediction of minimal pressure support during weaning from mechanical ventilation. Chest. 1993; 103:1215-9.

32. Zerah F, Harf A, Perlemuter L, Lorino H, Lorino AM, Atlan G. Effects of obesity on respiratory resistance. Chest. 1993:103:1470-6.

33. Vaschetto R, De Jong A, Conseil M, Galia F, Mahul M, Coisel Y, et al. Comparative evaluation of three interfaces for non-invasive ventilation: a randomized cross-over design physiologic study on healthy volunteers. Crit Care. 2014;18:R2.

34. Mancebo J, Isabey D, Lorino H, Lofaso F, Lemaire F, Brochard L. Comparative effects of pressure support ventilation and intermittent positive pressure breathing (IPPB) in non-intubated healthy subjects. Eur Respir J. 1995:8:1901-9.

35. Kirton OC, DeHaven CB, Morgan JP, Windsor J, Civetta JM. Elevated imposed work of breathing masquerading as ventilator weaning intolerance. Chest. 1995:108:1021-5.

\section{Submit your next manuscript to BioMed Central and we will help you at every step:}

- We accept pre-submission inquiries

- Our selector tool helps you to find the most relevant journal

- We provide round the clock customer support

- Convenient online submission

- Thorough peer review

- Inclusion in PubMed and all major indexing services

- Maximum visibility for your research

Submit your manuscript at www.biomedcentral.com/submit 